\title{
17
}

\section{Microstructure of Bulk Nanomaterials Determined by X-Ray Line-profile Analysis}

\author{
Tamás Ungár, Erhard Schafler, and Jenö Gubicza
}

\subsection{Introduction}

The physical properties of structural materials are determined by their microstructure. The microstructure can be investigated either by direct methods, especially transmission or scanning electron microscopy (TEM or SEM), or by the indirect methods, like X-ray line-profile analysis (XLPA), differential scanning calorimetry (DSC), residual electrical resistivity (RER) or the different methods of mechanical testing. All these methods, irrespective of whether direct or indirect, reflect different aspects of the different microstructure features. The more methods that are used, the more comprehensive will be the microstructure characterization. In the present work the method of XLPA is summarized and discussed in comparison with other methods listed here. It is attempted to reveal how XLPA can contribute to a more complete characterization of the microstructure of bulk nanomaterials, especially when combined with other methods.

\section{2}

\section{General Concept and the Basic Ideas of X-ray Line-profile Analysis}

Within the framework of the kinematical scattering theory, the ideal diffraction pattern of a polycrystalline specimen consists of narrow, symmetrical, deltafunction-like peaks at the positions of the exact Bragg angles according to the well-defined unit cell of the crystal [1]. Several aberrations of the ideal powder pattern are related to the microstructure of materials and are the subject of XLPA. (i) Peak shift is related to internal stresses [2] or planar faults, especially stacking faults or twinning [1-4], or chemical heterogeneities [1]. (ii) Peak broadening indicates small crystallites [5-7], grains or subgrains [8], and/or the presence of microstresses [1, 9-14]. (iii) Stress gradients and/or chemical heterogeneities can also cause peak broadening [1, 15-17]. (iv) Peak asymmetries can be caused by long-range internal stresses $[12,13,16-20]$, planar faults $[3,4,21-$ 23] or chemical heterogeneities [1]. (v) Anisotropic peak broadening can result 
from anisotropic crystallite shape [24, 25] or anisotropic strain [9, 10, 26-32]. (vi) When the lattice parameter is large and the specimen has either a local or general texture, unusual peak narrowing can be observed, especially in the first few Bragg reflections [33,34]. Microstructure properties can be summarized at least into the following different categories: (1) internal stresses, (2) stacking faults, (3) twinning, (4) crystallite size or subgrains, (5) microstresses, (6) long-range internal stresses, (7) chemical heterogeneities, (8) anisotropic crystallite shape or (9) anisotropic strain. There is no one-to-one correlation between the different peak profile features and the different microstructure properties, as can be seen in Table 17.1, where the line-profile features and the microstructure elements are listed.

Both the different line-profile features and the different microstructure properties are complex, and the two sides, e.g. the experimental features and the microstructure properties, can be combined in many different ways. This fact makes it practically impossible (at least at this time) to have a general description of XLPA that would be able to treat all the microstructure properties by a unified general theory or model. It is the experimentator's task to select those microstructure properties that are most relevant to be considered in a particular experiment. At the same time, just because of the complexity of both the experiment and the microstructure properties, it is probably not possible to produce a model-independent general theory for XLPA. For the same reason, though there have been many attempts to develop model-independent descriptions of line

Table 17.1 Correlations between peak profile features, i.e. broadening, shifts, asymmetries or shape, and the different microstructure elements.

\begin{tabular}{|c|c|c|c|c|c|}
\hline $\begin{array}{l}\text { Peak profile features } \\
\text { Microstructure properties }\end{array}$ & $\begin{array}{l}\text { Peak } \\
\text { shift }\end{array}$ & $\begin{array}{l}\text { Peak } \\
\text { broadening }\end{array}$ & $\begin{array}{l}\text { Peak asym- } \\
\text { metry }\end{array}$ & $\begin{array}{l}\text { Anisotropic } \\
\text { peak } \\
\text { broadening }\end{array}$ & Peak shape \\
\hline Dislocations & & + & + & + & + \\
\hline Stacking faults & + & + & + & + & + \\
\hline Twinning & & + & + & + & + \\
\hline Microstresses & & + & & & \\
\hline $\begin{array}{l}\text { Long-range internal stress } \\
\text { or stress gradients }\end{array}$ & + & & + & + & \\
\hline Grain boundaries & + & + & & & \\
\hline Subboundaries & + & + & & & \\
\hline Internal stresses & + & & & & \\
\hline Coherency strains & + & + & + & + & \\
\hline $\begin{array}{l}\text { Chemical heterogeneities } \\
\text { or chemical gradients }\end{array}$ & + & + & + & & \\
\hline Point defects & & & & & + \\
\hline Precipitates, inclusions & + & & + & & + \\
\hline $\begin{array}{l}\text { Crystallite or grain } \\
\text { smallness or subgrains }\end{array}$ & & + & & + & + \\
\hline
\end{tabular}


broadening, these have not been too successful. In the present work a brief summary of XLPA is presented that is based on well-defined specific microstructure models, in particular on the model that the microstructure consists fundamentally of (a) subgrains with a simple and well-defined size distribution and that (b) the main source of microstrains are dislocations or dislocation-type lattice defects, e.g. triple junctions or sinter stresses.

\section{3}

\section{Basic Principles of X-ray Line-profile Analysis}

Assuming that size $(S)$ and lattice distortion $(D)$ are the two sources of X-ray line broadening, the profile of a Bragg reflection can be given by the convolution of the size and the distortion profiles [1]:

$$
I^{\mathrm{F}}=I^{\mathrm{S}} \times I^{\mathrm{D}}
$$

where the superscript $F$ indicates that $I^{\mathrm{F}}$ is the physical profile that does not contain instrumental effects. The Fourier transform of this expression is the Warren-Averbach equation [35]:

$$
\ln A(L) \cong \ln A_{\mathrm{L}}^{\mathrm{S}}-2 \pi^{2} L^{2} \mathrm{~g}^{2}\left\langle\varepsilon_{\mathrm{g}, L^{2}}\right\rangle
$$

where $A(L)$ are the absolute values of the Fourier coefficients of $I^{\mathrm{F}}, A_{\mathrm{L}}^{\mathrm{S}}$ are the size Fourier coefficients, $g$ is the absolute value of the diffraction vector and $\left\langle\varepsilon_{\mathrm{g}, L^{2}}\right\rangle$ is the mean square strain. $L$ is the Fourier length defined as $L=n a_{3}$, where $a_{3}=\lambda / 2\left(\sin \theta_{2}-\sin \theta_{1}\right), n$ are integers starting from zero, $\lambda$ is the wavelength of the X-rays and $\left(\theta_{2}-\theta_{1}\right)$ is the angular range of the measured diffraction profile. When strain is caused by dislocations or dislocation-type defects, $\left\langle\varepsilon_{\mathrm{g}, \mathrm{L}^{2}}\right\rangle$ can be expressed as [10]:

$$
\left\langle\varepsilon_{\mathrm{g}, L^{2}}\right\rangle=(b / 2 \pi)^{2} \pi \rho C f(\eta)
$$

where $\eta=L / R_{\mathrm{e}}, R_{\mathrm{e}}$ is the effective outer cutoff radius and $b$ is the Burgers vector of dislocations and $C$ is the contrast or orientation factor of dislocations. Wilkens determined the $f(\eta)$ function for parallel straight screw dislocations in the entire $L$ range from zero to infinity, see, e.g. Eqs. (A.6) to (A.8) in [10]. It can be shown that the Wilkens function, $f(\eta)$, has a more general validity, i.e. it is also valid for edge dislocations and for curved dislocations, and it can be extended in a simple way for infinitesimal dislocation dipoles when $M$ goes to zero, cf. [36], where $M=R_{\mathrm{e}} \sqrt{\rho}$ is the dislocation arrangement parameter [10,11]. $M$ is smaller or larger than unity if the dislocations have strong or weak dipole character, or in other words, when the effect of screening of the deformation fields is strong or weak, respectively $[10,14]$. 
17.3.1

\section{Strain Anisotropy}

Strain anisotropy means that neither the breadths nor the Fourier coefficients of the diffraction profiles are monotonous functions of the diffraction angle or $\mathrm{g}$ [27-32]. Strain anisotropy proved to be a powerful feature in XLPA, especially for determining Burgers-vector populations or active slip systems [37-49].

The orientation or $h k l$ dependence of the contrast of dislocations is well known in TEM. It is expressed explicitly in Eq. (17.3) by the contrast factor $C$. If dislocations are the major source of strain in a crystal the values of $C$ depend on the relative orientation of the Burgers, the line and the diffraction vectors, $\boldsymbol{b}$, $l$ and $g$, respectively. If either all possible slip systems in a crystal are more-orless equally populated or, if a polycrystal is more-or-less texture free, the contrast factors corresponding to one particular $h k l$ can be averaged over the permutations of these $h k l$ indices. It can been shown that, in a dislocated crystal, the average contrast factors, $\bar{C}$, are linear functions of the fourth-order invariants of $h k l$ [32]. For cubic crystals $\bar{C}$ is [32]:

$$
\bar{C}=\bar{C}_{\mathrm{h} 00}\left(1-q H^{2}\right)
$$

where $\bar{C}_{\text {h00 }}$ is the average dislocation contrast factor of the $h 00$ type reflections and $H^{2}=\left(h^{2} k^{2}+h^{2} l^{2}+k^{2} l^{2}\right) /\left(h^{2}+k^{2}+l^{2}\right)^{2}$. The values of $\bar{C}_{\mathrm{h} 00}$ and the $q$ parameter can be obtained numerically for different dislocation types as functions of the elastic properties of a crystal [37]. For hexagonal crystals $\bar{C}$ is [32, 43]:

$$
\bar{C}_{h k . l}=a+\frac{\left[\beta\left(h^{2}+k^{2}+i^{2}\right)+\gamma l^{2}\right] l^{2}}{\left[h^{2}+k^{2}+i^{2}+\frac{3}{2}\left(\frac{a}{c}\right)^{2} l^{2}\right]^{2}}
$$

where $\alpha, \beta$ and $\gamma$ are constants depending on the elastic constants of the crystal and the type of dislocations (e.g. basal, prismatic, pyramidal and/or any subslipsystem, or slip-system family) and on $c / a$, the ratio of the two lattice constants in the hexagonal crystal. The value of $a$ is the average contrast factor corresponding to the $h k .0$ reflection: $\bar{C}_{h k .0}=\alpha$. Equation (17.5) can be rationalized as $[43,50]$ :

$$
\bar{C}_{h k . l}=\bar{C}_{h k .0}\left[1+q_{1} x+q_{2} x^{2}\right]
$$

where $x=(2 / 3)(l / g a)^{2}, q_{1}=a_{1}$ and $q_{2}=-a_{1} \lambda^{-2}+a_{2}$. Equation (17.6) means that the average contrast factors corresponding to a specific slip system family (these are the 11 most likely slip systems in a hexagonal crystal according to Jones and Hutchinson [51]) and materials constants (lattice parameters and elastic constants) have to follow a parabola as a function of $x$. The $\bar{C}_{h k .0}=\alpha$ and the $q_{1}$ and $q_{2}$ parameters have been numerically evaluated and compiled for a large number of hexagonal crystals in [43]. 
17.3.2

\section{Breadth Methods}

The two simplest measures of peak broadening are the full width at half-maximum (FWHM) and the integral breadths, the two are denoted here as: $\Delta \mathrm{K}_{\mathrm{FWHM}}$ and $\Delta \mathrm{K}_{\beta}$, where $\Delta \mathrm{K}=(\cos \theta / \lambda) \Delta(2 \theta), \theta$ is the Bragg angle and $\Delta(2 \theta)$ is the FWHM or the integral breadth in radians, respectively. Since size is independent and strain is increasing with diffraction order, in order to separate size and strain effects, Williamson and Hall [52] suggested plotting the breadth of profiles versus $\sin \theta$. The extrapolated intercept of such a plot at $\sin \theta=0$ should give the inverse of an "apparent" size and the slope should be proportional to strain. A typical Williamson-Hall plot of a copper specimen deformed by equal channel angular pressing (ECAP) in a single pass is shown in Fig. 17.1(a). The

(a)

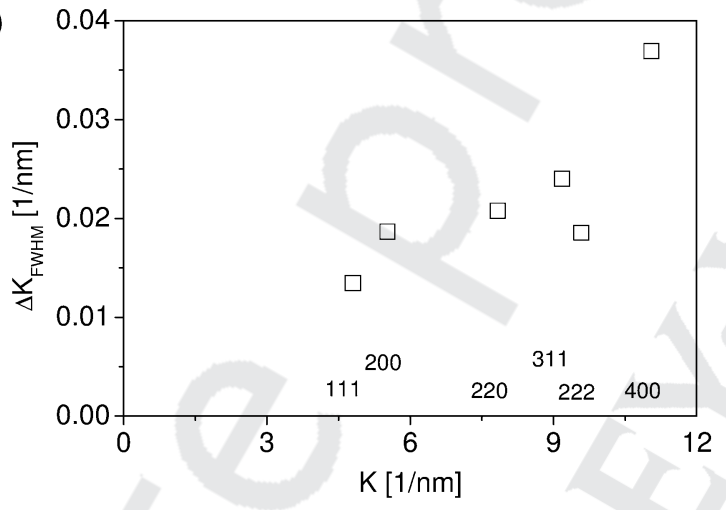

(b)

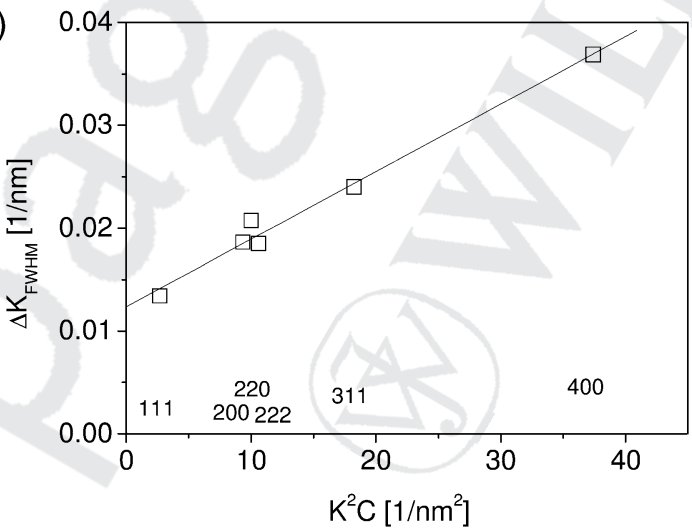

Fig. 17.1 The full width at half-maximum (FWHM) as a function of $K=2 \sin \theta / \lambda$ in the classical (a) $K \bar{C}^{2}$ in the modified Williamson-Hall plot (b) for Cu deformed by 1 ECAP pass, where $2 \theta$ and $\lambda$ are the diffraction angle and the $X$-ray wavelength and is the average dislocation contrast factor, respectively. 
apparent scattering of the data is far beyond experimental error, the figure indicates a strong strain anisotropy. This effect makes a simple interpretation of the Williamson-Hall plot impossible. However, strain anisotropy in the classical Williamson-Hall plot can be rationalized by the contrast factors of dislocations in the modified Williamson-Hall plot [30, 37, 40, 41, 53]. Two versions of the modified Williamson-Hall plot are suggested in [30, 53, 54]:

$$
\Delta K_{\mathrm{FWHM}} \text { or } \Delta K_{\beta}=0.9 / D+\left(\pi A^{2} b^{2} / 2\right)^{1 / 2} \rho^{1 / 2}\left(K \bar{C}^{1 / 2}+O\left(K^{2} \bar{C}\right)\right.
$$

and

$$
\Delta K_{\beta}=1 / d+a K^{2} \bar{C}+O\left(K^{2} \bar{C}\right)^{2}
$$

In Eq. (17.8) $D$ is an apparent crystallite size, $K=2 \sin \theta / \lambda$, $A$ is a constant depending on the $M$ parameter of dislocations, $b$ and $\rho$ are the Burgers vector and the average density of dislocations, respectively, and $O$ stands for higher-order terms in $K \bar{C}^{1 / 2}$. In Eq. (17.9) $d$ is an apparent crystallite size, $\alpha$ is a constant and $O$ stands for higher-order terms in $K^{2} \bar{C}$, not interpreted here. In [53] it has been shown by dimensionality analysis that the order dependent strain part of either the $\Delta K_{\mathrm{FWHM}}$ or the integral breadths, $\Delta K_{\beta}$, can only have even-power terms of $K$. Therefore, Eq. (17.8) is physically more appropriate. However, the breadth methods should only be used for qualitative purposes, as pointed out in [55], thus, both Eqs. (17.7) and (17.8) can be used alternatively. For spherical crystallites the volume-weighted mean diameter $\langle x\rangle_{\text {vol }}$ is directly related to $d$ : $\langle x\rangle_{\mathrm{vol}}=(4 / 3) d[5]$. The same data as in Fig. 17.1 (a), are plotted according to Eq. (17.8) in Fig. 17.1 (b), and show a smooth behavior versus $K^{2} \bar{C}$.

17.3 .3

Whole-profile Fitting Methods

The idea of whole-profile fitting goes back to Rietveld, who suggested producing the measured diffraction pattern by taking into account all possible effects that contribute to the intensity distribution, including all instrumental effects [56, 57]. The purpose of this method was to refine the structure parameters from powder-diffraction patterns. Well-defined analytical profile functions are used in the Rietveld method, such as the Voigt or pseudo-Voigt functions. However, profile shapes corresponding to dislocated crystals cannot be described by simple analytical functions $[9-14,17,18,37,53]$. Therefore procedures have been worked out, in which the diffraction pattern is simulated by using ab-initio physically established functions for both the size and the strain profiles [37, 42, 50, 53, 58]. In [53] and [58] the size profile, $I^{\mathrm{S}}$, is given by assuming either spherical or ellipsoidal crystallite shape and log-normal size distribution. In the case when spherical crystallite shape can be assumed, the function is defined by the two parameters of the size-distribution function: the median, $m$, and the variance, $\sigma$. The strain function, $I^{\mathrm{D}}$, is given by using the $f(\eta)$ Wilkens function, as 


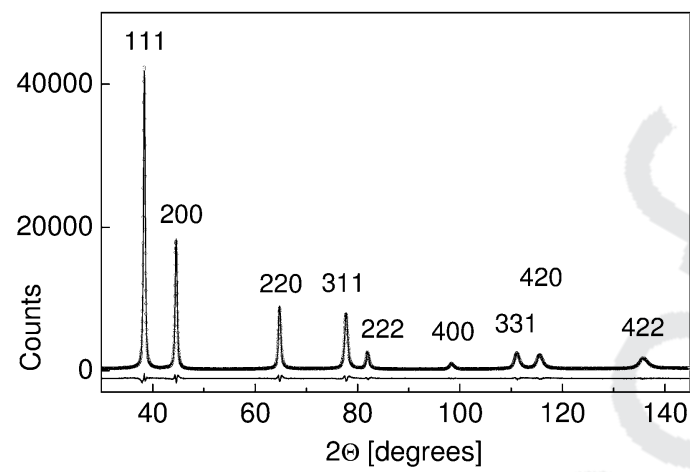

Fig. 17.2 The measured X-ray diffractogram (open circles) and the pattern obtained as a result of the CMWP fitting procedure (solid line) for Al$6 \mathrm{wt} . \% \mathrm{Mg}$ ball milled for $6 \mathrm{~h}$ [50].

defined in Eq. (17.3). The $I^{\mathrm{D}}$ function is defined by two parameters: the dislocation density, $\rho$ and the dislocation-arrangement parameter, $M$. This means that in the simplest case, together with the $q$ parameter in the contrast factors for cubic crystals, the numerical procedure is operating with five independent parameters: $m, \sigma, \rho, M$ and $q$. Here, we note that, due to the nature of the microstructure, this is the minimum number of parameters that have to be used. The instrumental profile, $I^{\mathrm{i}}$, has to be measured. The convolutional multiple whole-profile (CMWP) fitting procedure is a numerical method, producing the convolution of the three functions, $I^{\mathrm{S}}, I^{\mathrm{D}}$ and $I^{i}$, i.e. $I^{\mathrm{SIM}}=I^{\mathrm{S}} \times I^{\mathrm{D}} \times I^{i}$ [59]. The procedure is freely available through the web: http://www.renyi.hu/cmwp/. The background, $I^{\mathrm{BG}}$, is determined before the simulated $I^{\mathrm{SIM}}$ function is fitted to the measured diffraction pattern [38]. The measured X-ray diffractogram (open circles) and the pattern obtained as a result of the CMWP fitting procedure (solid line) for Al-6wt.\%Mg ball milled for $6 \mathrm{~h}$ is shown in Fig. 17.2. When individual profiles can be measured, the numerical procedure, called the multiple whole-profile (MWP) fitting procedure [50], is operating on the Fourier coefficients of the measured and the theoretical profiles. This method is also available at the same web address. The effect of stacking faults and twinning has been elaborated and incorporated into the CMWP procedure by evaluating the faulting effect on powder patterns of cubic crystals, for details see [23, 60].

\section{4}

Interpretation of Crystallite Size in Bulk Materials in Terms of Subgrains

Crystallite size determined by XLPA is often smaller than the grain or subgrain size obtained by TEM [45, 53, 60-64], especially when the material has been processed by plastic deformation. It can be shown that besides differences in orientation between grains or subgrains, cf. [65], subgrains separated by dipolar dislocation walls, but without differences in orientation, can also break down coherency of X-rays scattering [8]. Dipolar dislocation walls are one of the most 


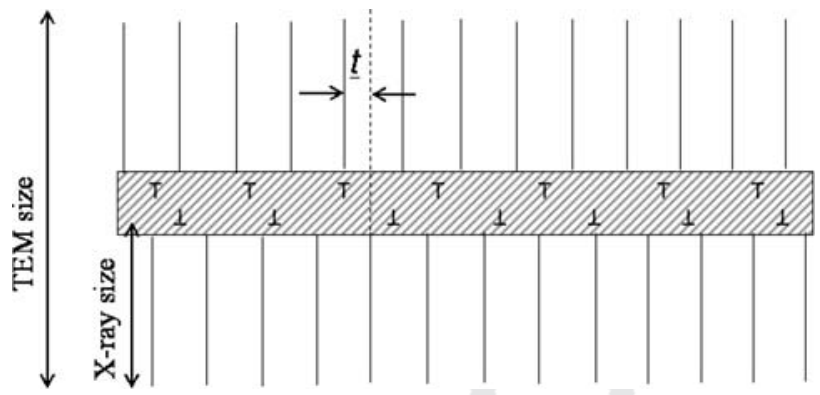

Fig. 17.3 A schematic dipolar dislocation wall. The symbol $t$ represents the shift of the two lattice-halves on the two sides of the dipolar wall.

common dislocation configurations in plastically deformed crystalline materials [66]. They do not cause tilt or twist between the two delineated regions [67] therefore, it is not trivial whether they break down coherent scattering $\boldsymbol{\omega}^{\mathbf{\omega}}$. A schematic dipolar dislocation wall is shown in the striated region in Fig. 17.3. In [8] it was shown that the lattice planes on the two sides of the dipolar dislocation wall will be shifted relative to each other as shown schematically in the figure. The shift, $t$, is varying randomly from subgrain to subgrain between $t=0$ and $t=b / 2$, where $b$ is the Burgers vector of dislocations. The shifts of the lattice planes induce phase shifts in the scattered X-rays. Since there is no correlation between the shifts caused by the different subgrains, the phase shifts on the scattered rays will also be uncorrelated. As a result, the intensities and not the amplitudes of the scattered rays will add up, which means that there will be no coherency between the rays scattered by the different subgrains, and the line broadening will be determined by the average subgrain size. The subgrains separated by small-angle grain boundaries or dipolar dislocation walls are shown schematically in Figs. 17.4 (a) and (b), respectively. The two models, i.e. the small-angle grain-boundary model, cf. [65], and the dipolar dislocation-wall model [8] of subgrain boundaries, provide together a physically well-established basis for the assumption that size and size-distributions determined by XLPA correspond to subgrains or dislocation cells. In those cases, however, when the subgrains and the metallographic or TEM grains are identical, as might happen in many cases, the TEM and X-ray size data can be identical. It has to be noted that, neither dipolar dislocation walls nor small-angle grain boundaries are such perfect arrays of dislocations as shown in Fig. 17.4. The arrays will not be perfectly regular and the dislocations may be of different type and/or orientation and/or sign. There may be some dipoles within the small-angle grain boundaries or, the dipolar walls may contain surplus dislocations of one sign causing orientation differences between the neighboring subgrains. The main message of the calculation in [8] is that dislocation subboundaries or dislocation walls break down the coherent scattering of X-rays, thus the X-ray size is probably closest to the subgrain size in bulk materials. 
(a)

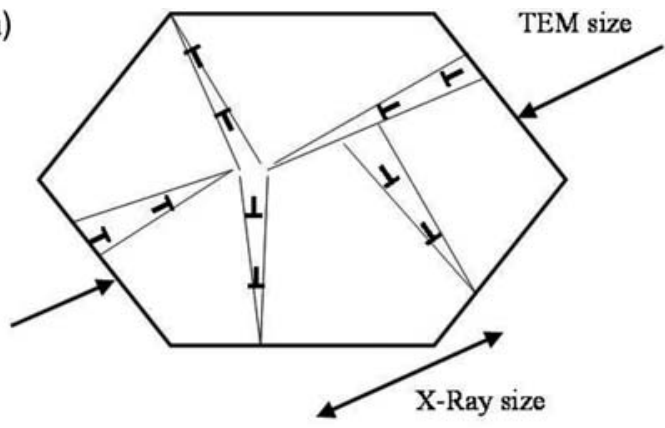

(b)

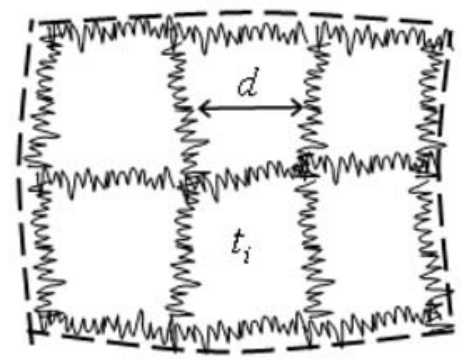

D

Fig. 17.4 (a) Schematic picture of subgrain or cell structure where dislocations constitute the boundaries of subgrains or cells with small misorientations. (b) A schematic representation of the structure of a grain interior containing dipolar dislocation walls. The randomly hatched regions are for the

subgrain boundaries, in the present case they are assumed to be dipolar dislocation walls. The thick dashed lines represent the large-angle grain boundaries. $D$ and $d$ are the grain and subgrain size, respectively. The lattice shift relative to the adjacent subgrain lattice in the $i$ th subgrain is $t_{\mathrm{i}}$.

\section{5}

Dislocation Structure of Bulk Nanomaterials Determined by X-ray Line-profile Analysis

17.5.1

Characteristic Parameters of the Dislocation Structure from Line Profiles

The X-ray line-profile analysis gives the density and the arrangement parameter of dislocations, $\rho$ and $M$, as well as the $q$ parameter(s) in the contrast factors of dislocations [50, 53]. The magnitude of $M$ describes the strength of the dipole character of dislocations: a higher $M$ value corresponds to a weaker dipole character, i.e. a weaker screening of the displacement fields of dislocations [53]. For polycrystalline cubic crystals the anisotropic contrast effect of dislocations on 
the peak broadening is characterized by one $q$ parameter, while for hexagonal structures two parameters, $q_{1}$ and $q_{2}$ are obtained from the evaluation of line profiles $[37,43,68]$.

The values of $q\left(q_{1}, q_{2}\right)$ parameter(s) are determined by the elastic constants and the dislocation slip systems activated in the crystal. For cubic structures, the Burgers vector of the prevailing dislocations is the shortest lattice vector. For example, in $f c c$ materials the Burgers vector is $1 / 2\langle 110\rangle$, while in $b c c$ structure it is $1 / 2\langle 111\rangle$. For a particular slip system, the value of the $q$ parameter depends on the angle between the dislocation line and Burgers vectors. The lower and upper limits of the $q$ values correspond to edge and screw dislocations, respectively. Assuming that the Burgers vector is the shortest lattice vector, the theoretical $q$ values for pure edge and screw dislocations in some frequently studied cubic materials are listed in Table 17.2 [37]. The comparison of the experimental $q$ value obtained from line-profile analysis with the theoretical values for pure edge and screw dislocations enables the determination of edge/screw character of prevailing dislocations. If the experimental $q$ value is close to the arithmetic average of the theoretical values for pure edge and screw dislocations, the dislocation structure has mixed character. When the experimental $q$ value is higher or lower than the theoretical average, the character of dislocations can be regarded as rather screw or rather edge, respectively.

In hexagonal materials the momentum of the shortest lattice vector equals the $a$ lattice parameter in the basal plane, therefore the directions of easy slip are the three $\boldsymbol{a}$-type directions. According to von Mises for plastic deformation of a polycrystalline material the activation of at least five independent slip systems is needed, therefore beside the three basal slip systems other dislocations should contribute to plastic flow. Moreover, the Burgers vectors of basal dislocations are perpendicular to the $c$-axis, therefore basal slips can not produce strain to the $c$ direction. Consequently, another nonbasal slip systems with Burgers vectors having a component parallel to the $c$-axis should be activated to deform hexagonal polycrystals. The prismatic and pyramidal slip systems and twinning are most probably required for plastic deformation of hexagonal polycrystals. As a consequence, all the eleven slip systems in hexagonal materials should be taken into account in studying the dislocation structure.

Table 17.2 The theoretically calculated values of $q$ parameter in the cases of pure edge, screw dislocations for some cubic materials [37].

\begin{tabular}{lll}
\hline & $\boldsymbol{q}$ (edge) & $\boldsymbol{q}$ (screw) \\
\hline $\mathrm{Al}$ & 0.36 & 1.33 \\
$\mathrm{Cu}$ & 1.68 & 2.37 \\
$\mathrm{Ni}$ & 1.42 & 2.24 \\
$\mathrm{Fe}$ & 1.28 & 2.67 \\
Diamond & 0.3 & 1.35 \\
\hline
\end{tabular}


Each of the eleven slip systems has different theoretical values of the $q_{1}$ and $q_{2}$ parameters, therefore the evaluation of the experimental $q_{1}$ and $q_{2}$ values enables the determination of the prevailing dislocation slip systems in the specimen. The theoretical $q_{1}$ and $q_{2}$ values for the eleven possible slip systems in the most common hexagonal materials have been calculated according to the work of Kužel and Klimanek [29] and listed in the paper of Dragomir and Ungár [43]. The eleven dislocation slip systems can be classified into three groups based on their Burgers vectors: $b_{1}=1 / 3\langle\overline{2} 110\rangle \quad\left(\langle\boldsymbol{a}\rangle\right.$ type), $b_{2}=\langle 0001\rangle(\langle\boldsymbol{c}\rangle$ type) and $b_{3}=1 / 3\langle\overline{2} 113\rangle(\langle\boldsymbol{c}+\boldsymbol{a}\rangle$ type). There are 4,2 and 5 slip systems in the $\langle\boldsymbol{a}\rangle,\langle\boldsymbol{c}\rangle$ and $\langle\boldsymbol{c}+\boldsymbol{a}\rangle$ Burgers vector groups, respectively. A computer program was elaborated to determine the Burgers-vector population from the measured values of $q_{1}^{(m)}$ and $q_{2}^{(m)}$ [46]. First, the program selects some slip systems from one of the three groups. In the second step the calculated $\bar{C}_{h k 0} q_{1}$ and $\bar{C}_{h k 0} q_{1}$ values of the selected slip systems are averaged with equal weights, where $\bar{C}_{h k 0}$ is the average contrast factor corresponding to the $h k 0$ type of reflections. This procedure is carried out for each of the three Burgers-vector groups. The relative fractions of the three groups, $h_{i}(i=1,2,3)$ are calculated by solving the following three equations:

$$
\begin{aligned}
& q_{1}^{(m)}=\frac{1}{P} \sum_{\mathrm{i}=1}^{3} h_{\mathrm{i}} b_{\mathrm{i}}^{2}\left(\overline{\overline{C_{h k 0} q_{1}}}\right)_{i} \\
& q_{2}^{(m)}=\frac{1}{P} \sum_{\mathrm{i}=1}^{3} h_{i} b_{\mathrm{i}}^{2}\left(\overline{\bar{C}_{\mathrm{hk} 0} q_{2}}\right)_{i}
\end{aligned}
$$

and

$$
\sum_{i=1}^{3} h_{i}=1
$$

where $\left(\overline{\bar{C}}_{h k 0 q_{1}}\right)_{i}$ and $\left(\overline{\bar{C}_{h k 0} q_{2}}\right)_{i}$ are obtained by averaging for the ith Burgers vector group and $P$ is given as $P=\sum_{i=1}^{3} h_{i} b_{i}^{2}\left(\overline{\bar{C}_{h k 0}}\right)_{i}$. If the three $h_{i}$ weights have positive values the program stores them as one of the possible solutions. After examining all the possible combinations of the slip systems (1395 combinations), ranges of the three weights are obtained as the final solution. The detailed description of the procedure is given in Ref. [46]. In the next two sections, results obtained on the dislocation structures in bulk cubic and hexagonal nanomaterials by X-ray line-profile analysis are summarized. 


\subsection{2}

\section{Dislocation Structure in Cubic Nanomaterials}

Severe plastic-deformation (SPD) techniques are effective methods for producing bulk, porosity- and contamination-free ultrafine-grained (UFG) or nanostructured materials. As the grain refinement during SPD-processed materials occurs by the arrangement of dislocations into dislocation walls that separate misoriented domains, the investigation of the dislocation structure is essential for understanding the evolution of fine-grained microstructure. Dislocations have been intensively studied in cubic metals [69] (Al [70], Al-alloys [70-72], $\mathrm{Cu}$ [73-80], Ni [81-83]) processed at room temperature by SPD procedures, e.g. by equal-channel angular pressing (ECAP) or high-pressure torsion (HPT). These two techniques are described in detail elsewhere [84]. One pass of ECAP corresponds to an equivalent strain value of about 1 . The imposed strain increases proportionally by the increase of the number of passes. It was found that the dislocation density increases with increasing strain for any studied cubic metals. As an example, the dislocation density versus the imposed strain for $\mathrm{Al}-3 \% \mathrm{Mg}$ specimen is plotted in Fig. 17.5 [70].

As the deformation proceeds, the dislocation arrangement parameter, $M$, decreases, indicating that dislocations are arranged into dipoles minimizing the energy of their strain field [71, 72, 74]. This arrangement of dislocations is associated with the formation of dislocation walls resulting in the decrease of crystallite size, as mentioned above. After room-temperature SPD processes, the $q$ parameter is usually close to or less than the arithmetic mean of the theoretical values for pure edge and screw dislocations, which indicates a rather edge type character of the dislocation structure. This can be explained by the annihilation of screw dislocations resulted by their relatively easy cross-slip. It was shown that the parameters of the dislocation structure saturate after about 4 ECAP passes at room temperature for $\mathrm{Al}$ [70], Al-Mg alloys [70], commercial Al-Mg-Si alloy (Al 6082) [72] and $\mathrm{Cu}$ [74] specimens. This saturation was also observed after 3 revolutions of HPT for Al-Mg-Sc-Zr alloys [71]. The saturation values correspond to the dynamic equilibrium state between formation and annihilation

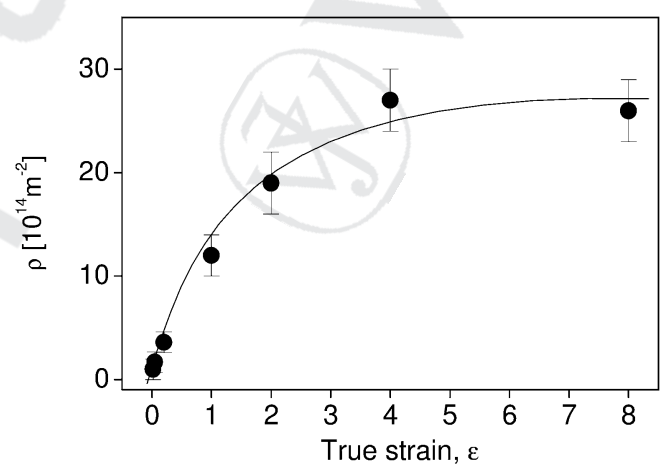

Fig. 17.5 The dislocation density $(\rho)$ for $\mathrm{Al}_{3} \mathrm{Mg}$ processed by ECAP as a function of the imposed strain [70]. 
Table 17.3 The measured saturation values of the areaweighted mean crystallite size $\left(\langle x\rangle_{\text {area }}\right)$, the dislocation density $(\rho)$ for different fcc metals processed by SPD methods [69].

\begin{tabular}{lcc}
\hline Sample & $\begin{array}{c}\langle\boldsymbol{x}\rangle_{\text {area }} \\
{[\mathbf{n m}]}\end{array}$ & $\boldsymbol{\rho}\left[1 \mathbf{1 0}^{14} \mathbf{m}^{-2}\right]$ \\
\hline Al, 8ECAP & $272 \pm 30$ & $1.8 \pm 0.3$ \\
Al-1\%Mg, 8ECAP & $88 \pm 10$ & $3.9 \pm 0.4$ \\
Al-3\%Mg, 8ECAP & $65 \pm 7$ & $23 \pm 2$ \\
$\mathrm{Cu}, 8 \mathrm{ECAP}$ & $64 \pm 7$ & $26 \pm 3$ \\
$\mathrm{Ni}$, 8ECAP+6HPT & $48 \pm 6$ & $25 \pm 2$ \\
\hline
\end{tabular}

of dislocations. The maximum dislocation densities at room temperature for different cubic materials are listed in Table 17.3. The saturation value of the dislocation density is higher for a metal where the annihilation of dislocations is more difficult. For example, in $\mathrm{Al}-3 \% \mathrm{Mg}$ alloy the $\mathrm{Mg}$ atoms hinder the dislocation motion, consequently the maximum dislocation density is approximately 13 times higher than for Al [70]. As grain refinement in SPD metals occurs by the arrangement of dislocations into cell boundaries, the higher dislocation density results in a decrease of crystallite size for higher $\mathrm{Mg}$ concentrations. The higher saturation dislocation density at room temperature for $\mathrm{Cu}$ compared to $\mathrm{Al}$ is explained by the lower self-diffusion rate as the dislocation annihilation is controlled by the diffusion of vacancies [76]. It should be noted, however, that several authors have found that after 12-16 ECAP passes at room temperature the dislocation density in $\mathrm{Cu}$ decreased as a result of dynamic recovery [75].

The combination of SPD procedures was applied to achieve further grain refinement in pure Ni $[82,83]$. HPT and cold rolling were carried out on specimens processed by ECAP previously. It was found that the additional deformation after ECAP resulted in a further grain refinement $(46 \mathrm{~nm})$ and an increase of the dislocation density up to $25 \times 10^{14} \mathrm{~m}^{-2}$, which can be reached after 8 ECAP passes and additional 5 revolutions of HPT. However, the specimen produced by electrodeposition has even finer microstructure $(24 \mathrm{~nm})$ and much higher dislocation density $\left(82 \times 10^{14} \mathrm{~m}^{-2}\right)$ than the materials processed by any combination of SPD methods.

The thermal stability of the ultrafine-grained microstructure is an important issue from the point of view of the practical application of nanomaterials. The recovery of the dislocation structure and the recrystallization in SPD processed ultrafine-grained fcc metals has been extensively studied [76, 85]. The crystallite size and the dislocation density as a function of the annealing temperature were measured for Ni deformed by HPT [85] and ECAP-processed $\mathrm{Cu}$ [76]. The differential scanning calorimetry (DSC) measurements of $\mathrm{Cu}$ samples show a broad exothermic peak that corresponds to the recovery of the microstructure. The maximum of the exothermic peak in the DSC trace shifted to lower temperature values and the heat released during the annealing increases with the increase of strain and saturate at about $\varepsilon=4$. The increase of the stored energy can be at- 
tributed to the rise of the dislocation density with increasing strain. The higher strain energy raises the driving force for nucleation of new dislocation-free grains, i.e. the recovery starts at lower temperatures [76].

The dislocation density and the area-weighted mean crystallite size as a function of the temperature at the DSC curve for a $\mathrm{Cu}$ specimen processed by 8 ECAP passes are shown in Fig. 17.6 [76]. At the temperature corresponding to the beginning of the DSC peak, each X-ray profile appears to be the sum of a narrow and a broad peak. This special shape of the diffraction lines has been also observed by Kužel [78] for a copper sample deformed by HPT under 6 GPa pressure and annealed at $250^{\circ} \mathrm{C}$ for $100 \mathrm{~min}$. In Fig. 4 in [76] the intensity distribution of the 200 Bragg reflection is shown in linear (a) and double-logarithmic (b) scales, respectively. This figure shows that the intensity distribution goes through a well-defined inflection point at around $\Delta K \sim 0.006 \mathrm{~nm}^{-1}$, indicating that the diffraction profile consists of two peaks. It was found that the broad peak can be well approximated by the profile measured before the heat-treatment, which suggests that the broad subprofile corresponds to the nonrecovered regions of the material. The profile for the non annealed specimen (the solid lines in Fig. 4 in [76]) matches perfectly the tail part of the peak recorded after annealing (open circles in Fig. 4 in [76]) after dividing the intensity by an appropriate factor. The difference between the two profiles (the solid line and the open circles) gives a sharp peak that is related to the recovered volume of the material. The other peaks of the specimen quenched from $500 \mathrm{~K}$ can be also decomposed into narrow and broad subprofiles. At the temperature corresponding to the maximum of the DSC peak, the mean crystallite size is about 8 times higher, while the dislocation density is 50 times lower than before annealing. After the DSC peak the crystallite size and the dislocation density reach their

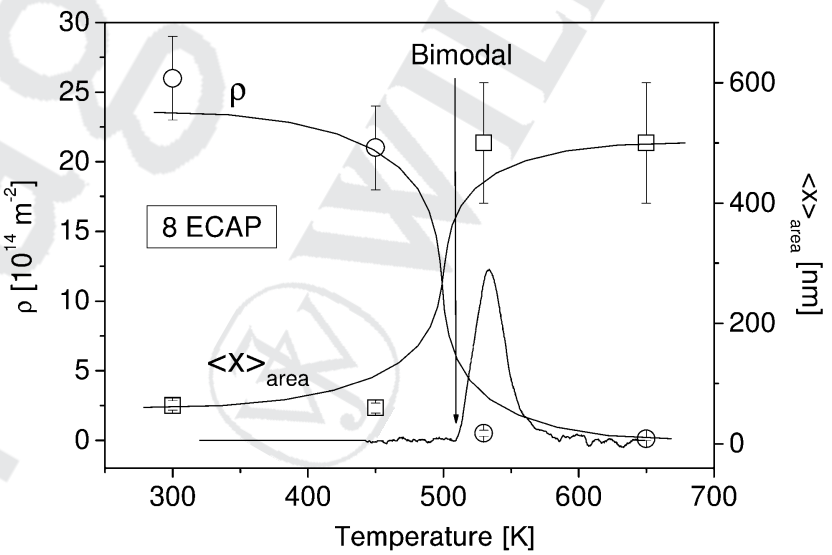

Fig. 17.6 The dislocation density and the area-weighted mean crystallite size as a function of temperature for $\mathrm{Cu}$ processed by 8 ECAP passes. The DSC curve obtained at $40 \mathrm{~K} / \mathrm{min}$ is also shown in the figure [76]. 


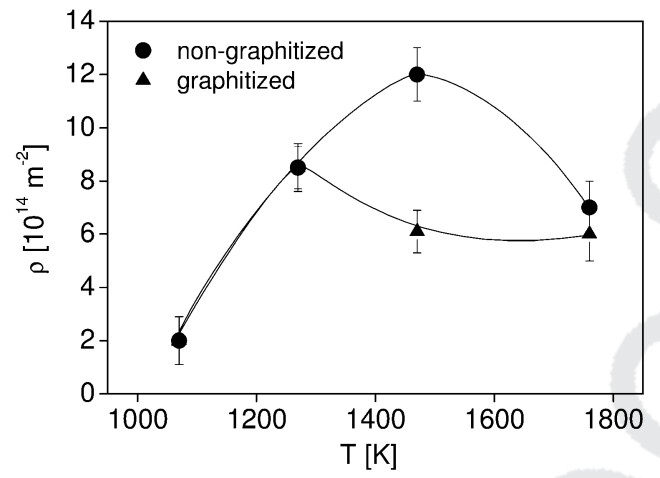

Fig. 17.7 Dislocation density in graphitized and nongraphitized samples of nanocrystalline diamond as a function of the sintering temperature [86]

highest and lowest limiting values, $500 \mathrm{~nm}$ and $10^{13} \mathrm{~m}^{-2}$, respectively, which are detectable by X-ray peak profile analysis.

Besides the UFG metals processed by SPD methods, X-ray line-profile analysis has been also applied for the characterization of the dislocations structure in nonmetallic bulk cubic nanomaterials. Nanostructured diamond specimens were prepared from micrometer-sized $(30-40 \mu \mathrm{m})$ synthetic diamond powder by high-pressure-high-temperature (HPHT) compaction at a pressure of $2.0 \mathrm{GPa}$ and at selected temperatures in the 1070-1760 K range [86]. The increase of the dislocation density during HPHT compression is associated with the decrease of the crystallite size down to about $50-100 \mathrm{~nm}$. The grain refinement in HPHTtreated diamond results from the rearrangement of the dislocation structure into a lower-energy configuration. The density of dislocations was always greater in samples that were compressed and heated in water-free environments (did not graphitize) than in partially graphitized samples [86]. At the lowest temperatures used in the experiments the difference in the population of dislocations between the two sets of samples was very small, but quickly increased and reached a maximum at $1470 \mathrm{~K}$ and then decreased with further increase in temperature, as shown in Fig. 17.7, cf. [86-88].

\subsection{3}

\section{Dislocations in Hexagonal Nanomaterials}

For obtaining fine-grained microstructure with high dislocation density SPD procedures were applied also to hexagonal metals, e.g. on commercially pure $\mathrm{Ti}$ [45, 63, 64, 74, 89-91] and AZ91 Mg alloy [92]. Generally, the SPD processes on hexagonal materials are carried out at elevated temperatures because of the rigidity of the specimens at room temperature. In a commercially pure Ti specimen processed by 8 ECAP passes at $400-450^{\circ} \mathrm{C}$, the dislocation density obtained from X-ray line-profile analysis is $44-10^{14} \mathrm{~m}^{-2}$. The relative fractions of the $\langle a\rangle,\langle c\rangle$ and $\langle c+a\rangle$ Burgers vectors are $62 \%, 0-4 \%$ and $32-36 \%$, respectively. The abundance of $\langle a\rangle$-type dislocations besides the $\langle c\rangle$ - and $\langle c+a\rangle$-type dislocations has been also found for other bulk hexagonal nanomaterials, e.g 
sintered WC [93, 94] and SPD processed Mg alloys [93]. This observation is in agreement with TEM results carried out on other coarse-grained specimens [95]. The relatively high fraction of $\langle c+a\rangle$ dislocations in Ti processed by ECAP can be attributed to the high temperature of deformation. Theoretical calculations and TEM observations for hexagonal metallic materials suggest the activation of $\langle c+a\rangle$ dislocations by strong deformation at elevated temperatures [45]. At room temperature the critical resolved shear stress of pyramidal $\langle c+a\rangle$ dislocations is about five times larger than that for basal slip [96], but this value decreases with increasing temperature.

The thermal stability of the ultrafine-grained microstructure in Ti was investigated by DSC [74]. The volume-weighted mean crystallite size and the dislocation density as a function of temperature are shown in Fig. 17.8. It can be seen that the recovery of the dislocation structure starts before the appearance of the exothermic DSC peak. At $800 \mathrm{~K}$, where the DSC peak starts, the dislocation density has already decreased from $44 \times 10^{14} \mathrm{~m}^{-2}$ to $9 \times 10^{14} \mathrm{~m}^{-2}$. However, the increase of the crystallite size accelerates only after $800 \mathrm{~K}$. The dislocation density decreases further after $800 \mathrm{~K}$ and at $850 \mathrm{~K}$ it has a value of $8 \times 10^{13} \mathrm{~m}^{-2}$. As the temperature increases the relative fraction of the $\langle c+a\rangle$-type dislocations decreases to between 0 and $4 \%$, indicating that these dislocations disappear faster than the $\langle a\rangle$ or $\langle c\rangle$-type ones (see Fig. 17.9). This can be explained by the fact that the $\langle c+a\rangle$-type dislocations have larger Burgers vectors and consequently higher formation energies than the other two types.

The ECAP process of AZ91 magnesium alloy was also carried out at high temperature $\left(270^{\circ} \mathrm{C}\right)$ [92]. The main alloying elements in the AZ91 alloy are 9 wt.\% Al, 1 wt.\% $\mathrm{Zn}$ and $0.2 \mathrm{wt} . \% \mathrm{Mn}$. The dislocation density increases from $0.4 \times 10^{14} \mathrm{~m}^{-2}$ to $2 \times 10^{14} \mathrm{~m}^{-2}$ and the mean crystallite size decreases from 563 $\mathrm{nm}$ to $97 \mathrm{~nm}$ as a result of 8 ECAP passes. It was found that before ECAP the

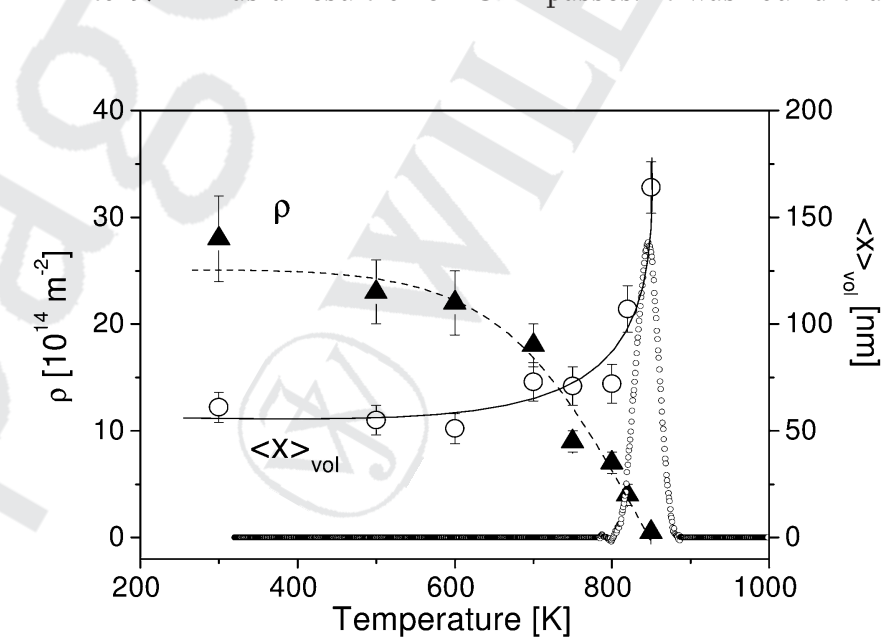

Fig. 17.8 The dislocation density, the volume-weighted mean crystallite size and the heat flow as a function of annealing temperature for Ti processed by ECAP [74]. 


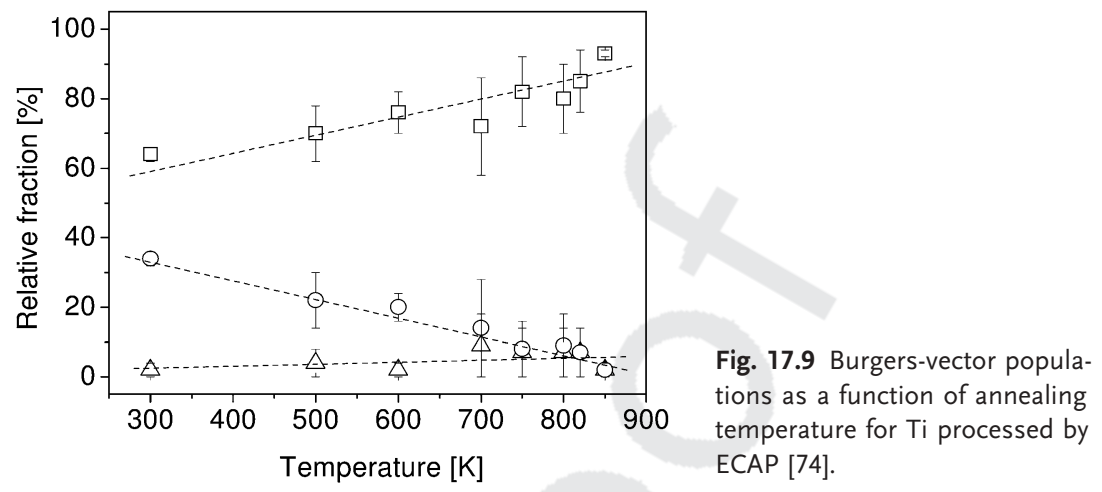

relative fractions of the $\langle a\rangle,\langle c\rangle$ and $\langle c+a\rangle$ Burgers vectors are $68-86 \%, 0-15 \%$ and $0-14 \%$, respectively. The abundance of $\langle a\rangle$-type dislocations can be explained similarly as for Ti. After high-temperature ECAP the relative fractions of the $\langle a\rangle,\langle c\rangle$ and $\langle c+a\rangle$ Burgers vectors are changed to $54-58 \%, 0-2 \%$ and $38-42 \%$, respectively. The increase of the relative fraction of $\langle c+a\rangle$ dislocations results from the strong deformation at high temperature. The specimen processed by 8 ECAP passes was further deformed by tension at different temperatures [92]. At relatively low temperature the dominance of $\langle a\rangle$-type dislocations can be established. At high temperature, i.e. at $300{ }^{\circ} \mathrm{C}$, the relative fraction of the $\langle a\rangle$ Burgers vector types decreases and the relative fraction of $\langle c+a\rangle$ dislocations increases. This is in agreement with the general observation that $\langle c+a\rangle$ dislocations are activated during strong plastic deformation at elevated temperatures.

\section{6}

Vacancies and X-ray Line-profile Analysis

It is well known that during conventional deformation beside dislocations vacancies are also formed, which during severe plastic deformation may be enforced. The mechanisms of plastic deformation and strain hardening in largestrain deformation, i.e. in stages IV and V are relevant for severe plastic-deformation modes, with the additional feature of an enhanced hydrostatic-pressure component $[97,98]$. The specific evolution of lattice defect types and their densities, their interaction mechanisms and arrangements control the hardening behavior, but also seem to be responsible for the enhanced ductility that has been repeatedly observed as a special feature of SPD metals [97-99]. In particular, the deformation-induced vacancies appear to play a major role here.

Since electrical resistivity [100] and calorimetric measurements [101] provide the total concentration of vacancies together with dislocations, whereas XLPA gives only the dislocation density [10,17], the combination of these three different types of investigations enable determination of the vacancy and dislocation 
densities separately. It is shown further that in-situ diffuse X-ray scattering measurements at a synchrotron radiation source can also provide information about the evolution of lattice defects, especially of vacancies, and about vacancy distribution in grain-interior and grain-boundary regions.

The diffuse scattering from crystals containing defects with displacements was first calculated by Eckstein [102] and Huang [103], and in more detail in [104-106]. For more details about diffuse scattering of point defects see [107-116].

Here, we show that a systematic analysis of the diffuse background scattering corresponding to deformed metals can be interpreted in terms of point defect production. In-situ XLPA measurements were carried out at the ELETTRA synchrotron in Trieste [20]. Single- and polycrystalline copper specimens of high purity have been deformed in compression by a compact test machine mounted on a 5 -axis goniometer for the compensation of the shape and orientation changes during the deformation process. The (400) peak profiles of the specimen were measured in reflection by a linear position-sensitive detector (OED-50 Braun, Munich). A [001]-oriented Cu single crystal and a polycrystalline copper specimen of about $80 \mu \mathrm{m}$ average grain size have been investigated in situ with a very low strain rate $\dot{\varepsilon} \sim 5 \times 10^{-5} \mathrm{~s}^{-1}$. The diffraction peaks were recorded in 30 to $60 \mathrm{~s}$, in this time the true strain deformation $\varepsilon$ was less than $10^{-3}$. More details of such an in-situ synchrotron experiment can be found in [20]. From the diffraction peaks the dislocation densities were evaluated by the procedure described in Section 17.3 and in detail in [20] by fitting the Wilkens-type strain profile functions to the measured profiles according to the numerical procedure described in $[50,53]$. Due to the low noise of the detector the increase of the background to peak ratio, $R$, is considered to be a physical effect due to the increase of the diffuse scattering caused by point defects, in particular by vacancies and/or vacancy clusters.

In the case of the undeformed specimens only a vanishing background intensity was observed, for the single as well as the polycrystal. With increasing deformation the diffuse background intensity increased considerably. For the quantification of the diffuse background scattering, the ratio of the integrated background, $A_{\mathrm{BG}}$, and the integrated peak intensity, $A_{\text {Peak }}, R=A_{\mathrm{BG}} / A_{\text {Peak }}$, was defined according to Fig. 2 in [117]. The evolution of $R$ as a function of strain can be seen in Figs. 4 (a) and (b), in [117], on linear and logarithmic scales, respectively. It has been found that in the polycrystalline specimen the ratio, $R_{\mathrm{PX}}$, increases much faster at the initial strain values than the ratio, $R_{\mathrm{SX}}$, in the single-crystalline sample and that $R_{\mathrm{PX}}$ remains much larger than $R_{\mathrm{SX}}$ throughout the entire deformation range.

During plastic deformation vacancies and dislocations are produced concomitantly, cf. [118-123]. Experimental data suggest that the vacancy concentration, $C_{\mathrm{vac}}$ starts increasing with the dislocation density, $\rho$, only beyond a certain threshold and saturates at very large $\rho$ values. The correlation between the average vacancy concentration, $C_{\mathrm{vac}}$, and the dislocation density measured in $10^{14} \mathrm{~m}^{-2}$ units, $\rho_{14}$, is determined on the basis of data obtained on specimens deformed by cold rolling, $C_{\mathrm{vac}}^{\mathrm{CR}}$, and by ECAP, $C_{\mathrm{vac}}^{\mathrm{ECAP}}[80,124,125]$ : 


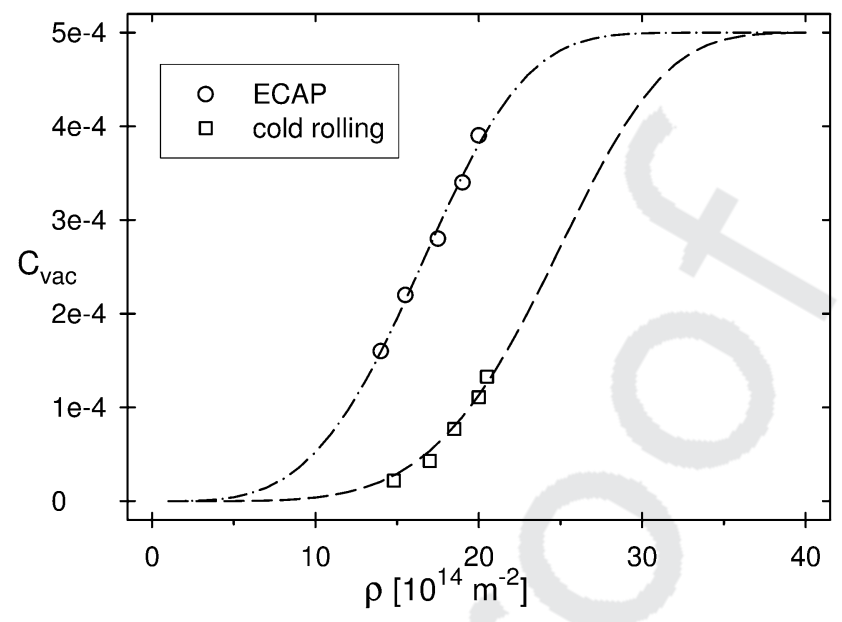

Fig. 17.10 The vacancy concentrations determined from the difference between the true and apparent dislocation densities determined by the X-ray and calorimetric or residual electrical resistivity methods. The

open circles or squares correspond to copper specimens deformed by ECAP and interrupted cold rolling, respectively. The dashed and dash dotted lines correspond to Eqs. (17.12a) and (17.12b), respectively [125].

$$
\begin{aligned}
C_{\mathrm{vac}}^{\mathrm{CR}} & \cong 5 \times 10^{-4}\left\{1-\exp \left[-8 \times 10^{-8}\left(\rho_{14}\right)^{5}\right]\right\} \\
C_{\mathrm{vac}}^{\mathrm{ECAP}} & \cong 5 \times 10^{-4}\left\{1-\exp \left[-2.2 \times 10^{-5}\left(\rho_{14}\right)^{3.7}\right]\right\}
\end{aligned}
$$

Equations (17.12a) and (17.12b) are shown in Fig. 17.10 with the measured data points for cold-rolled and ECAP-deformed $\mathrm{Cu}$, respectively. The saturation value of $C_{\mathrm{vac}}^{\mathrm{SAT}}=5 \times 10^{-4}$ has been determined as the lowest value that can satisfy Eqs. (17.12) for both sets of experimental data. In Fig. 7 in [117] it has been shown that the diffuse background scattering ratios for the single crystal, $R_{\mathrm{SX}}$, and polycrystal, $R_{\mathrm{PX}}$ specimens are proportional to the dislocation densities, i.e. $\left(R_{\mathrm{PX}} / \rho_{14}^{\mathrm{PX}}\right) \cong 13\left(R_{\mathrm{SX}} / \rho_{14}^{\mathrm{SX}}\right)$. This indicates a much faster vacancy accumulation in the polycrystalline specimen. The polycrystal is considered as a composite of grain boundary (GB) and grain interior or matrix (M) regions. It can be assumed that the vacancy production rates in the single crystal and in the matrix (of the polycrystal) are the same, thus the average vacancy concentration in the polycrystal can be given as the weighted sum of vacancy concentrations in the matrix and GB regions:

$$
C_{\mathrm{vac}}^{\text {average }}=f_{\mathrm{GB}} C_{\mathrm{vac}}^{\mathrm{GB}}+\left(1-f_{\mathrm{GB}}\right) C_{\mathrm{vac}}^{\mathrm{M}}
$$

where $f_{\mathrm{GB}}$ is the volume fraction of the grain boundary (GB) region, and $C_{\mathrm{vac}}^{\mathrm{GB}}$ and $C_{\mathrm{vac}}^{\mathrm{M}}$ are the local vacancy concentrations in the grain-boundary and the matrix regions. Assuming a volume fraction of the grain-boundary region of about $5 \%$, the average vacancy concentration then can be given to the two regions pro 


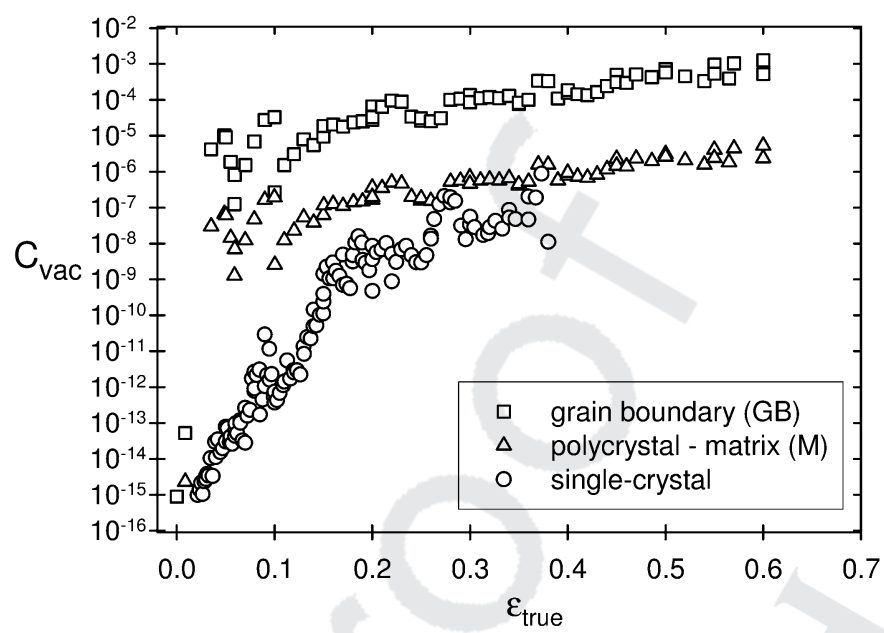

Fig. 17.11 The local vacancy concentrations, produced by plastic deformation, as a function of true strain $\varepsilon$, in the single-crystal (open circles), and in the grain-interior (open triangles) and grain-boundary (open squares) regions in the polycrystalline specimens, respectively [125].

rata. In Fig. 17.11 the vacancy concentrations in the single-crystal specimen and the local vacancy concentrations in the matrix and in the grain-boundary region are shown. In the single-crystalline state the vacancy concentration increases by about 8 orders of magnitude during deformation up to $\varepsilon \sim 40 \%$. The evolution in the matrix (or grain interior) region is similar, while in the grain-boundary region the vacancy concentration grows much stronger to extremely high values between $10^{-4}$ and $10^{-3}$ corresponding to those at the melting point of copper. We note that these vacancy concentrations are the excess vacancy concentrations produced and stored during plastic deformation. The extremely large vacancy concentration values, especially in the GB region are probably present in the form of free volumes, rather than single vacancies, as results from molecular dynamics simulation suggest (D. L. McDowell, private communication).

From these more qualitative considerations it follows that the storage of vacancies or free volume produced during plastic deformation depends (i) on the structure and volume fraction of grain boundaries in the crystal (ii) on the deformation mode and conditions. The latter is indicated by the variation of factor and exponent in Eqs. (17.12a) and (17.12 b) for two different cases. 


\section{7}

\section{Stacking Faults and Twinning in Nanostructured Materials Determined by $\mathrm{X}$-ray Line-profile Analysis}

The formation of planar defects, especially twinning has been shown to be an important mechanism, alternative to dislocation glide, even in materials of high stacking-fault energy, like aluminum and copper, when the grain size is reduced below a certain critical value [54, 60, 126-139]. In one of the models of deformation twinning the authors suggested that the critical stress to move a twinning partial increases slower with decreasing grain size than for lattice dislocations [127]. This model, however, turns out not to be supported by experimental data in the literature [128]. An alternative model was worked out, according to which an optimum grain-size range can be found in which the critical stress for the nucleation of deformation twins is lower than the stress necssary to move full dislocations [129-133]. Zhu and coworkers [134] have shown the existence of deformation twins in copper produced by high-pressure torsion (HPT). A model was developed in which leading and trailing partials form deformation twins where the trailing partials are less mobile than the leading one, thus creating large twins. Nongeometrically necessary dislocations at grain boundaries play an important role in the model that are substantiated by experiment and theory [135-137]. Both, experiment and the model suggest critical grain sizes, below which twinning occurs in $\mathrm{Cu}$ and $\mathrm{Al}$ at about 40 and $20 \mathrm{~nm}$, respectively.

A systematic method to determine the density of intrinsic and extrinsic stacking faults, and twin boundaries together with the dislocation density and arrangement, and the average grain size and grain-size distribution, by X-ray lineprofile analysis, has been developed recently $[23,138]$. The effect of stacking faults, and twin boundaries on X-ray diffraction patterns was calculated numerically by using the DIFFaX software of Treacy et al. [4] for the first 15 Bragg reflections in $f c c$ crystals up to $20 \%$ fault densities [23]. It was found that the Bragg reflections consist of 5 types of subreflections, where the subreflection types are determined by specific conditions of the $h \mathrm{kl}$ indices, in good agreement with the theory developed in the early 1950 s by Warren [1]. It was shown that the profiles of the subreflections are of Lorentzian- (or Cauchy-) type functions. Analyzing about 15000 subreflections the breadths (FWHM) and the shifts relative to the exact Bragg angles were determined. The values of FWHM and shifts of the subreflections were given by 5th-order polynomials as a function of the densities of intrinsic and extrinsic stacking faults, and twin boundaries, $\beta_{\text {intr }}, \beta_{\text {extr }}$ and $\alpha$, respectively. The coefficients of the 5 th-order polynomials and the fractions of the different subreflection types were compiled in three separate data files that are accessible at the website: http://metal.elte.hu/ $\sim$ levente/stacking. The data files were incorporated into the CMWP software $[50,53,59]$ for evaluating planar faults together with dislocations and crystallite and/or subgrain-size distributions. The extended software, eCMWP, was applied to inert-gas condensed nanocrystalline [54, 139-141], and submicrometer grainsize copper specimens deformed by the method of ECAP [142, 143]. The X-ray 
line-profile analysis results substantiated the TEM results of the group of Zhu [127, 129-131, 133, 134], that in copper twinning becomes essential below a critical crystallite or subgrain size, of about $40 \mathrm{~nm}$.

\section{8}

\section{Conclusions}

1. It has been shown that X-ray line-profile analysis can be used as a powerful tool to characterize the microstructure of bulk nanomaterials in terms of (i) grains or subgrains, (ii) dislocation densities, (iii) Burgers-vector population and slip activity, (iv) stacking faults and twin boundaries, and (v) excess vacancy concentrations.

2. Whenever this was possible, the data provided by the X-ray method, have been analyzed in comparison with TEM results. It has been shown that either there is a good correlation between the X-ray and TEM results, or, if there are differences, these can be used to learn more details about the microstructure, especially in terms of grains versus subgrains.

3. It is found that bulk nanomaterials produced by severe plastic deformation, usually contain extremely high dislocation densities up to the order of $10^{16} \mathrm{~m}^{-2}$, and these values have been confirmed by high-resolution TEM investigations.

4. The discrepancy between dislocation densities determined by the X-ray method or TEM and other procedures like residual electrical resistivity (RER) or differential scanning calorimetry (DSC) has been shown to enable the determination of excess vacancy concentrations produced by plastic deformation. It has been shown that the methods of RER and DSC provide an apparent dislocation density, a part of which can, and has to, be expressed in terms of vacancy concentration.

5. It has been shown that the dislocation mechanism is replaced by faulting or twinning when the grain or subgrain size becomes smaller than certain critical values, of about 40 and $20 \mathrm{~nm}$ in the case of copper and aluminium, respectively, in good correlation with TEM observations.

6. It has been shown that the breadth methods provide a very useful qualitative guidance, before more sophisticated full-profile methods are applied.

\section{Acknowledgements}

The authors are grateful to the Hungarian National Science Foundation, OTKA T46990, F47057 and T43247, for supporting this work. 


\section{References}

1 B. E. Warren 1996, X-ray Diffraction, Dover Publications, New York.

2 I. C. Noyan, J. B. Cohen 1987, Residual Stress Determination by Diffraction, Springer, Berlin.

3 A. J. C. Wilson 1962, The Diffraction of X-Rays by Finite and Imperfect Crystals, in X-Ray Optics, London, Methuen.

4 M. M. J. Treacy, J. M. Newsam, M. W. Deem 1991, Proc. Roy. Soc. London A 433, 499.

5 J. I. Langford, D. Louer 1991, J. Appl. Crystallogr. 24, 149.

6 N. C. Popa, D. Balzar 2002, J. Appl. Crystallogr. 35, 338.

7 J. I. Langford, D. Louër, P. Scardi 2000, J. Appl. Crystallogr. 33, 964.

8 T Ungár, G Tichy, J Gubicza, R Hellmig 2005, Powder Diff. 20, 366.

9 M. A. Krivoglaz 1996, Theory of X-ray, Thermal Neutron Scattering by Real Crystals, Springer-Verlag, Berlin.

10 M. Wilkens 1970, Fundamental Aspects of Dislocation Theory, J. A. Simmons, R. de Wit, R. Bullough (eds.), Vol. II. Nat. Bur. Stand. (US) Spec. Publ. No. 317, Washington, DC. USA, p. 1195.

11 M. Wilkens 1970, phys. stat. sol. (a) 2 , 359.

12 I. Gaál 1984, in Proceedings of the 5th Riso International Symposium on Metallurgy Materials Science, (eds.) N. H. Andersen, M. Eldrup, N. Hansen, D. Juul Jense, T. Leffer, H. Lifholt, O. B. Pedersen, B. N. Singer, Riso Nat. Lab, Roskilde, Denmark, p. 245.

13 I. Groma, T. Ungár, M. Wilkens 1988 , J. Appl. Crystallogr. 21, 47.

14 I. Groma 1998, Phys. Rev. B 57, 7535.

15 E. Macherauch, V. Hauk 1986, (eds.) Residual Stresses in Science and Technology, DGM-Informationsstelle, Germany.

16 H. Mughrabi 1983, Acta Metall. 31, 1367.

17 T. Ungár, H. Mughrabi, D. Rönnpagel, M. Wilkens 1984, Acta Metall. 32, 333.

18 H. Mughrabi, T. Ungár, W. Kienle, M. Wilkens 1986, Philos. Mag. A 53, 793.

19 H. Mughrabi, T. Ungár 2002, in Dislocations in Solids, F. R. N. Nabarro,
M. S. Duesbury (eds.), Vol. 11, NH

Elsevier, Amsterdam, p. 343.

20 E. Schafler, K. Simon, S. Bernstorff, P. Hanák, G. Tichy, T. Ungár, M. J. Zehetbauer 2005, Acta Mater. 53, 315.

21 A. I. Ustinov, L. O. Olikhovska, N. M. Budarina, F. Bernard 2004, in Diffraction Analysis of the Microstructure of Materials, E. J. Mittemeijer, P. Scardi (eds.) Springer, Berlin-Heidelberg, pp. 309.

22 E. Estevez-Rams, M.Leoni, P. Scardi, B. Aragon-Fernandez, H. Fuess 2003, Philos. Mag. 83, 4045.

23 L. Balogh, G. Ribárik, T. Ungár 2006, J. Appl. Phys. 100, 023512.

24 A.Guinier 1963, X-ray Diffraction, Freeman, San Francisco, CA.

25 P. Scardi, M. Leoni 1999, J. Appl. Crystallogr. 32, 671.

26 A. R. Stokes, A. J. C. Wilson 1944, Proc. Cambridge Philos. Soc. 40, 197.

27 G. Caglioti, A. Paoletti, F. P. Ricci 1958, Nucl. Instrum. 3, 223.

28 P. Klimanek, R. Kužel Jr. 1988, J. Appl. Crystallogr. 21, 59.

29 R. Kužel Jr., P. Klimanek 1988, J. Appl. Crystallogr. 21, 363.

30 T. Ungár,A. Borbély 1996, Appl. Phys. Lett. 69, 3173.

31 P. W. Stephens 1999, J. Appl. Crystallogr. 32, 281.

32 T. Ungár, G. Tichy 1999, phys. stat. sol. (a) $171,425$.

33 D. Rafaja, V. Klemm, G. Schreiber, M. Knapp, R. Kužel 2004, J. Appl. Crystallogr. 37, 613.

34 G. Ribárik, N. Audebrand, H. Palancher, T. Ungár, D. Lour 2005, J. Appl. Crystallogr. 38, 912.

35 B. E. Warren, B. L. Averbach 1950 J. Appl. Phys. 21, 595.

36 F. F. Csikor, I. Groma 2004, Phys. Rev. B 70, 064106.

37 T. Ungár, I. Dragomir, Á. Révész, A. Borbély 1999, J. Appl. Crystallogr. 32. 992.

38 P. Chatterjee, S. P. Sen Gupta 1999 , J. Appl. Crystallogr. 32, 1060. 
39 R. Cerny, J. M. Joubert, M. Latroche, A. Percheron-Guegan, K. Yvon 2000, J. Appl. Crystallogr. 33, 997.

40 R. W. Cheary, E. Dooryhee, P. Lynch, N. Armstrong, S. Dligatch 2000, J. Appl. Crystallogr. 33, 1271.

41 P. Chatterjee, S. P. Sen Gupta 2001, Philos. Mag. A 81, 49.

42 P. Scardi, M. Leoni 2002, Acta Crysallogr. A 58, 190.

43 C. Dragomir, T. Ungár 2002, J. Appl. Crystallogr. 35, 556.

44 E. Schafler, Ch. Sitkovitch, I. Dragomir, Á. Révész, M. Zehetbauer, T. Ungár 2000, Mater. Sci. Forum 321-324, 92.

45 Y. T. Zhu, J. Y. Huang, J. Gubicza, T. Ungár, Y. M. Wang, E. Ma, R. Z. Valiev 2003, J. Mater. Res. 18, 1908.

46 K. Máthis, K. Nyilas, A. Axt, I. D. Cernatescu, T. Ungár, P. Lukáè 2004, Acta Mater. 52, 2889.

47 P. Cordier, T. Ungár, L. Zsoldos, G. Tichy 2004, Nature, 428, 837.

48 I. C. Dragomir, D. S. Li, G. A. CastelloBranco, H. Garmestani, R. L. Snyder, G. Ribárik, T. Ungár 2005, Mater. Charac. 55, 66.

49 E. Schafler, M. Zehetbauer 2005, Rev. Adv .Mater. Sci. 10, 28.

50 G. Ribárik, T. Ungár, J. Gubicza 2001, Mater. Sci. Eng. A, 34. 669.

51 I. P. Jones, W. B. Hutchinson 1981, Acta Metall. 29, 951.

52 G. K. Williamson, W. H. Hall 1953, Acta Metall. 1, 22.

53 T. Ungár, J. Gubicza, G. Ribárik, A. Borbély 2001, J. Appl. Crystallogr. 34, 298.

54 T. Ungár, S. Ott, P. Sanders, A. Borbély, J. R. Weertman 1998, Acta Mater. 46, 3693.

55 P. Scardi, M. Leoni, R. Delhez 2004, J. Appl. Crystallogr. 37, 381.

56 H. M. Rietveld 1969, J. Appl. Crystallogr. 2, 65.

57 P. Suortti 1993, in The Rietveld Method, IUCr Monographs on Crystallography, R.

$<$ QA $>$ place of publication?
59 G. Ribárik, J. Gubicza, T. Ungár 2004, Mater. Sci. Eng. A 387-389, 343.

60 T. Ungár, L. Balogh, Y. T. Zhu, C. Xu, G. Ribárik, Z. Horita, T. G. Langdon 2006, in Proc. Ultrafine Grained Materials IV, Y. T. Zhu, T. G. Langdon, Z. Horita, M. J. Zehetbauer, S. L. Semiatin, T. C. Lowe (eds.), The Minerals, Metals \& Materials Society, Warrendale, USA.

61 T. Ungár, M. Victoria, P. Marmy, P. Hanák, G. Szenes 1999, Nucl. Instrum. Methods A. 11995. 1.

62 T. Ungár, M. Victoria, P. Marmy 2000, J. Nucl. Mater. 276, 278.

63 J. Gubicza, I. C. Dragomir, G. Ribárik, S. C. Baik, Y. T. Zhu, R. Z. Valiev, T. Ungár 2003, Z. Met.kd. 94, 1185.

64 J. Gubicza I. C. Dragomir, G. Ribárik, Y. T. Zhu, R. Z. Valiev, T. Ungár 2003, Mater. Sci. Forum, 414-415, 229.

65 R. E. Bolmaro, H. G. Brokmeier, J. W. Signorelli, A. Fourtz, M. A. Bertinetti 2004, in Diffraction Analysis of the Microstructure of Materials, E. J. Mittemeijer, P. Scardi, P. (eds.), Springer, BerlinHeidelberg, p. 391.

66 D. Kuhlmann-Wilsdorf 2002, in Dislo- <QA $>$ place of cations in Solids, F. R. N.Nabarro, M. S. publication? Duesbery (eds.), Elsevier, p. 211. ம́ </QA>

67 M. Wilkens, T. Ungár, H. Mughrabi 1987, phys. stat. sol. (a) 104, 157.

68 A. Borbely, I. Dragomir-Cernatescu, G. Ribarik, T. Ungar 2003, J. Appl. Crystallogr. 36, 160.

69 J. Gubicza, N. Q. Chinh, Gy. Krállics, I. Schiller, T. Ungár 2006, Curr. Appl. Phys. 6, 194.

70 J. Gubicza J., N. Q. Chinh, Z. Horita, T. G. Langdon 2004, Mater. Sci. Eng. A 387-389, 55

71 D. Fátay, E. Bastarash, K. Nyilas, S. Dobatkin, J. Gubicza, T. Ungár 2003, Z. Met.kd. 94, 842.

72 J. Gubicza, Gy. Krállics, I. Schiller, D. Malgin 2004, Mater. Sci. Forum 473 474, 453.

73 A. Dubravina, M. J. Zehetbauer, E. Schafler, I. V. Alexandrov 2004, Mater. Sci. Eng. A 387, 817. sity Press, p. 167.

58 T. Ungár, P. Martinetto, G. Ribárik, E. Dooryhée, Ph. Walter, M. Anne 2002, J. Appl. Phys. 91, 2455.
74 J. Gubicza, N. H. Nam, L. Balogh, R. J. Hellmig, V. V. Stolyarov, Y. Estrin, T. Ungár 2004, J. Alloys Compd. 378, 248. 
75 F. Dalla Torre, R. Lapovok, J. Sandlin, P. F. Thomson, C. H. J. Davies, E. V. Pereloma 2004, Acta Mater. 52, 4819.

76 J. Gubicza, L. Balogh, R. J. Hellmig, Y. Estrin, T. Ungár 2005, Mater. Sci. Eng. A 400-401, 334.

77 R. Kužel, Z. Matej, V. Cherkaska, J. Pesicka, J. Cízek, I. Procházka, R. K. Islamgaliev 2004, J. Alloys Compd. 378, 242.

78 R. Kužel, M. Cernansky, V. Holy, J. Kubena, D. Simek, J. Kub 2004, in: Diffraction Analysis of the Microstructure of Materials, E. J. Mittemeijer, P. Scardi (eds.), Springer, Berlin, p. 229.

79 E. Schafler, G. Steiner, E. Korznikova, M. Kerber, M. J. Zehetbauer 2005, Mater. Sci. Eng. A 410-411, 169.

80 E. Schafler, A. Dubravina, B. Mingler, H. P. Karnthaler, M. Zehetbauer 2006, Mater. Sci. Forum, 503-504, 51.

81 W. Skrotzki, R. Tamm, R. Klemm, E. Thiele, C. Holste, H. Baum 2002, Mater. Sci. Forum, 408, 667.

82 A. P. Zhilyaev, J. Gubicza, G. Nurislamova, Á. Révész, S. Suriñach, M. D. Baró, T. Ungár 2003, phys. stat. sol. (a) 198, 263.

83 A. P. Zhilyaev, J. Gubicza, S. Suriñach, M. D. Baró, T. G. Langdon 2003, Mater. Sci. Forum 426, 4507.

84 R. Z. Valiev, R. K. Ishlamgaliev, I,V. Alexandrov 2000, Prog. Mater. Sci. 45, 103.

85 E. Schafler, R. Pippan 2004, Mater. Sci. Eng A 387-389, 799.

86 C. Pantea, J. Gubicza, T. Ungár, G. Voronin, T. W. Zerda 2002, Phys. Rev. B, 66, 094106.

87 C. Pantea, J. Gubicza, T. Ungár, G. A. Voronin, N. H. Nam, T. W. Zerda 2004, Diamond Relat. Mater. 13, 1753.

88 G. A. Voronin, T. W. Zerda, J. Gubicza, T. Ungár, S. N. Dub 2004, J. Mater. Res. 19, 2703.

89 E. Schafler, L. Zeipper, M. J. Zehetbauer 2004, in Proc. 2nd International Conference on Nanomaterials by Severe Plastic Deformation: Fundamentals Processing - Applications, M. J. Zehetbauer, R. Z. Valiev (eds.) Wien, Austria, Wiley-VCH Weinheim, Germany, pp. 426-432.
90 L. F. Zeipper, M. J. Zehetbauer, Ch. Holzleithner 2005, Mater. Sci. Eng. A 410-411, 217.

91 B. Mingler, V. V. Stolyarov, M. Zehetbauer, W. Lacom, H. P. Karnthaler 2006, Mater. Sci. Forum 503-504, 805.

92 K. Máthis, J. Gubicza, N. H. Nam 2005, J. Alloys Compd. 394, 194.

93 J. Gubicza, G. Ribárik, G. R. GorenMuginstein, A. R. Rosen, T. Ungár 2001, Mater. Sci. Eng. A 309-310, 60.

94 T. Ungár, J. Gubicza 2002, Z. Met.kd. 93, 694.

95 D. R. Chichili, R. K. T. Ramesh, K. J. Hemker 1998, Acta Mater. 46, 1025.

96 M. H. Yoo 1981, Metall. Trans. A 12, 12.

97 M. Zehetbauer, H. P. Stuewe, A. Vorhauer, E. Schafler, J. Kohout 2003, Adv. Eng. Mater. 5, 330.

98 M. Zehetbauer, J. Kohout, A. Dubravina, E. Schafler, A. Vorhauer 2004, J. Alloys Compd. 378, 329.

99 M. J. Zehetbauer, L. Zeipper, E. Schafler 2005, in Proc. NATO-ARW Workshop Nanostructured Materials by HighPressure Severe Plastic Deformation, Y. Zhu, V. Varyukhin (eds), Donetsk, Ukraine, Nato Science Series II: Mathematics, Physics and Chemistry, Vol. 212, Springer Berlin.

100 M. Zehetbauer 1994, Key Eng. Mater. 97-98, 287.

101 M. B. Beaver, D. L. Holt, A. L. Titchener 1973, Prog. Mater. Sci. 17, 5.

102 H. Eckstein 1945, Phys. Rev. 68, 120.

103 K. Huang 1947, Proc. R. Soc. A, 190, 102.

104 R. Cochran, G. Kartha 1956, Acta Crystallogr. 9, 941.

105 B. Borie 1959, Acta Crystallogr. 12, 280

106 M. A. Krivoglaz 1969, Theory of X-Ray and Thermal Neutron Scattering by Real Crystals, Plenum Press, New York.

107 T. O. Baldwin, F. A. Sherrill, F. W. Young 1968, J. Appl. Phys. 39, 1541.

108 R. Collella, A. Merlini 1966, phys. stat. sol. $14,81$.

109 S. B. Austermann, K. T. Miller 1965, phys. stat. sol. 11, 241.

110 R. G. Perret, D. T. Keating 1967, in: Small Angle X-Ray Scattering, H. Brum- 
berger (ed.), Gordon, Breach, New York, p. 373.

111 H. Trinkhaus, H. Spalt, H. Peisl 1970, phys. stat. sol. (a) 2, K97.

112 W. Schmatz 1970, in: Vacancies and Interstitials in Metals, A. Seeger et al. (eds.), North Holland, Amsterdam, p. 589.

113 P. Ehrhart, W. Schilling 1973, Phys. Rev. B, 8, 2604.

114 H. Trinkhaus 1972, phys. stat. sol. (b) 51, 307.

115 P. H. Dederichs 1970, Phys. Rev. B, 1, 1306.

116 P. H. Dederichs 1973, J. Phys. F, 3, 471.

117 T. Ungár, E. Schafler, P. Hanák, S. Bernstorff, M. Zehetbauer 2005, Z. Met.kd. 96, 578.

118 A. Seeger 1955, Handbuch der Physik III, Springer-Verlag, Berlin.

$<$ QA $>$ author initials? $</ \mathrm{QA}>$

$<$ QA $>$ still in print? $</ Q A>$
119 Kovács 1967, Acta Metall. 15, 1731.

120 A. Van den Beukel 1970, in Vacancies and Interstitials in Metals, A. Seeger et al. (eds.), North Holland, Amsterdam, p. 427.

121 H. G. Van Bueren 1955, Acta Metall. 3, 519.

122 G. Saada 1963, in: Electron Microscopy and Strength of Crystals, G. Thomas, J. Washburn (eds.), Interscience, New York.

123 U. Essmann, U. Goesele, H. Mughrabi 1981, Philos. Mag. A, 44, 405.

124 M. Zehetbauer, E. Schafler, T. Ungár 2005, Z. Met.kd. 96, 1044.

125 T. Ungár, E. Schafler, P. Hanák, S. Bernstorff, M. Zehetbauer 2006, Mater. Sci. Eng A, in print.

126 M. Chen, E. Ma, K. J. Hemker, H. Sheng, Y. M. Wang, X. Cheng 2003, Science. 300, 1275.

127 X. Z. Liao, J. Y. Huang, Y. T. Zhu, F. Zhou, E. J. Lavernia 2003, Philos. Mag. 83, 3065.
128 M. A. Meyers, O. Vöhringer, V. A. Lubarda 2001, Acta Mater. 49, 4025.

129 X. Z. Liao, F. Zhou, E. J. Lavernia, D. W. He, Y. T. Zhu 2003, Appl. Phys. Lett. 83, 5062.

130 X. Z. Liao, Y. H. Zhao, Y. T. Zhu, R. Z. Valiev, D. V. Gunderov 2004, J. Appl. Phys. 96, 636.

131 X. Z. Liao, Y. H. Zhao, S. G. Srinivasan, Y. T. Zhu, R. Z. Valiev, D. V. Gunderov 2004, Appl. Phys. Lett. 84, 592.

132 R. J. Asaro, P. Krysl, B. Kad 2003, Philos. Mag. Lett. 83, 733.

133 Y. T. Zhu, X. Z. Liao, S. G. Srinivasan, Y. H. Zhao, M. I. Baskes, F. Zhou, E. J. Lavernia 2004, Appl. Phys. Lett. 85, 5049.

134 Y. T. Zhu, X. Z. Liao, S. G. Srinivasan, E. J. Lavernia 2005, J. Appl. Phys. 98, 034319/1-8.

135 Z. Budrovic Van Swygenhoven, H. Derlet, P. M. Van Petegem, S. B. Schmitt 2003, Science, 304, 273.

136 J. Schiøtz, K. W. Jacobsen 2003, Science. 301, 1357.

137 H. Van Swygenhoven, P. M. Derlet, A. G. Frøseth 2004, Nature Mater. 3, 399.

138 T. Ungár, L. Balogh, Y. T. Zhu, Z. Horita, C. Xu, T. G. Langdon 2006, Mater. Sci. Eng. accepted for publication.

$<$ QA $>$ publicated? $<\mid \mathrm{QA}>$

139 J. R. Weertman, P. G. Sanders 1994, Solid State Phenom. 35-36, 249.

140 P. G. Sanders 1996, Ph. D. Thesis, Northwestern University, Evanston, IL, USA 60208.

141 P. G. Sanders, G. E. Fougere, L. J. Thompson, J. A. Eastman, J. R. Weertman 1997, Nanostruct. Mater. 8, 243.

142 R. Z. Valiev, E. V. Kozlov, Yu. F. Ivanov, J. Lian, A. A. Nazarov, B. Baudelet 1994, Acta Metall. Mater. 42, 2467.

143 T. Ungár, J. Gubicza, P. Hanák, I. Alexandrov 2001, Mater. Sci. Eng. A, 319321, 274. 